\title{
Ventriculoperitoneal shunt related meningioma: a case report
}

\author{
G.A. Cruz-Ortiz ${ }^{1}$, A. Samano-Osuna ${ }^{1}$, M. Jimenez-Jimenez ${ }^{1}$, H.R. Alvis- \\ Miranda $^{3}$, A. Lee ${ }^{2}$, L.R. Moscote-Salazar ${ }^{1}$ \\ ${ }^{1}$ Hospital Juarez de Mexico, Mexico D.F. \\ ${ }^{2}$ Hospital Angeles del Pedregal. Mexico D.F. \\ ${ }^{3}$ Universidad de Cartagena, Cartagena de Indias, Colombia
}

\begin{abstract}
Meningiomas are the most common primary, non-glial tumours of the brain and spine, and represent the most common extra-axial lesions. The typical meningioma is a dural-based, markedly enhancing extraaxial mass; they exhibit cortical buckling with trapped cerebrospinal fluid clefts or cortical vessels. There are factors strongly associated with risk of developing meningioma, as in the case of exposure to ionizing radiation, or exogenous or endogenous hormones, as in this case, the presence of shunt material as a foreign body may have contributed to oncogenesis on the basis of a chronic inflammatory reaction. The aim of this report is to present the clinical case of a meningioma, which enveloped the proximal catheter of ventriculoperitoneal shunt valve.
\end{abstract}

Key words: meningioma, ventriculoperitoneal shunt, oncogenesis.

\section{Introduction}

Meningiomas are the most common primary, non-glial tumours of the brain and spine, and represent the most common extra-axial lesions, accounting for $13-20 \%$ of all intracranial tumours (2). They are predominantly benign neoplasms that are derived from meningothelial cells [i.e., arachnoid cap cells (12)], almost all corresponding to grade I of the WHO histopathologic classification (10). Less than $10 \%$ ever cause clinical symptoms (6).

Their incidence rates range from 1.2 to 11.5 per $100.000(19,9,5)$. The typical meningioma is a dural-based, markedly enhancing extra-axial mass; they exhibit cortical buckling with trapped cerebrospinal fluid clefts or cortical vessels (6). The most common locations include over the cerebral convexity, in the parasagittal region, or arising from the sphenoid wing (6). The aim of this report is to present the clinical case of a meningioma, which enveloped the proximal catheter of ventriculoperitoneal (VP) shunt valve.

\section{Case report}

A 44 y.o. female patient, with prior history of basal arachnoiditis 12 years ago due to neurocysticercosis which left a residual bilateral amaurosis, plus ventriculoperitoneal shunt placing in the same year and 3 shunt revisions in the following four years due to hardware dysfunction. The current condition has 5month of evolution, consisting of holocraneal headache of gradual and progressive course, which partially decrease with analgesics and subsequently accompanied by intermittent episodes of 
left predominance hypoesthesia and decreased strength on the same side.

On examination, we observed that higher mental functions were kept, with Glasgow coma scale (GCS) of 15 points; commitment of the II cranial nerve, consisting in pale papilla with bilateral amaurosis; muscle strength $3 / 5$ in the left hemibody and ipsilateral hyperreflexia and Babinski. The patient presented astereoagnosia and left finger agnosia also. The cranial MRI showed a right heterogeneous frontoparietal lesion on the hardware way, which on the gadoliniumT1WI phase showed homogeneous enhancement; FLAIR with moderate perilesional edema (Figure 1).

A right fronto-parietal craniotomy was performed (Figure 2A); evidencing a lesion of grayish-white appearance, rubbery consistency, regularly vascularized, which enveloped the catheter valve so both were removed entirely (Figure 2B). The histopathological study reported a meningioma (Figure 3).

\section{Discusion}

Meningiomas are benign tumours derived from the arachnoid villous structures of the meninges and are common in the central nervous system (8). Histologically the meninges comprise many different cell types (18) including macrophages, dendritic cells, mast cells and fibroblasts (20), and it is known that meningothelial cells of the inner and outer layer of the arachnoid give rise to meningiomas (17).At computed tomography (CT), typical diagnostic features include a well-circumscribed, smooth mass with a broad dural attachment (6). In $75 \%$ of cases, the meningioma is hyperdense, with homogeneous enhancement after the administration of contrast material (6).
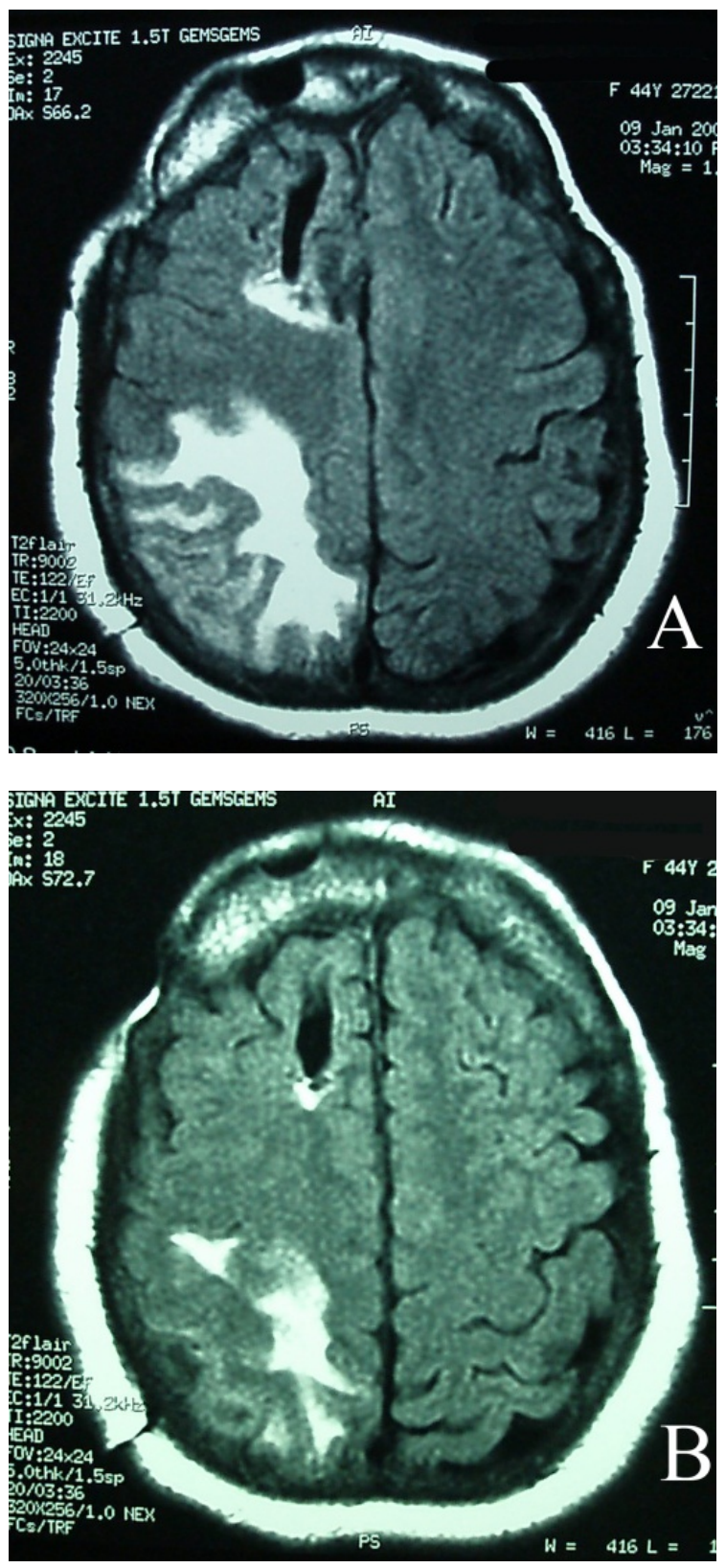

Figure 1

(A) Brain MRI showed a right heterogeneous frontoparietal lesion on the hardware way, which on the gadolinium-T1WI phase showed homogeneous enhancement;(B) FLAIR with moderate perilesional edema 

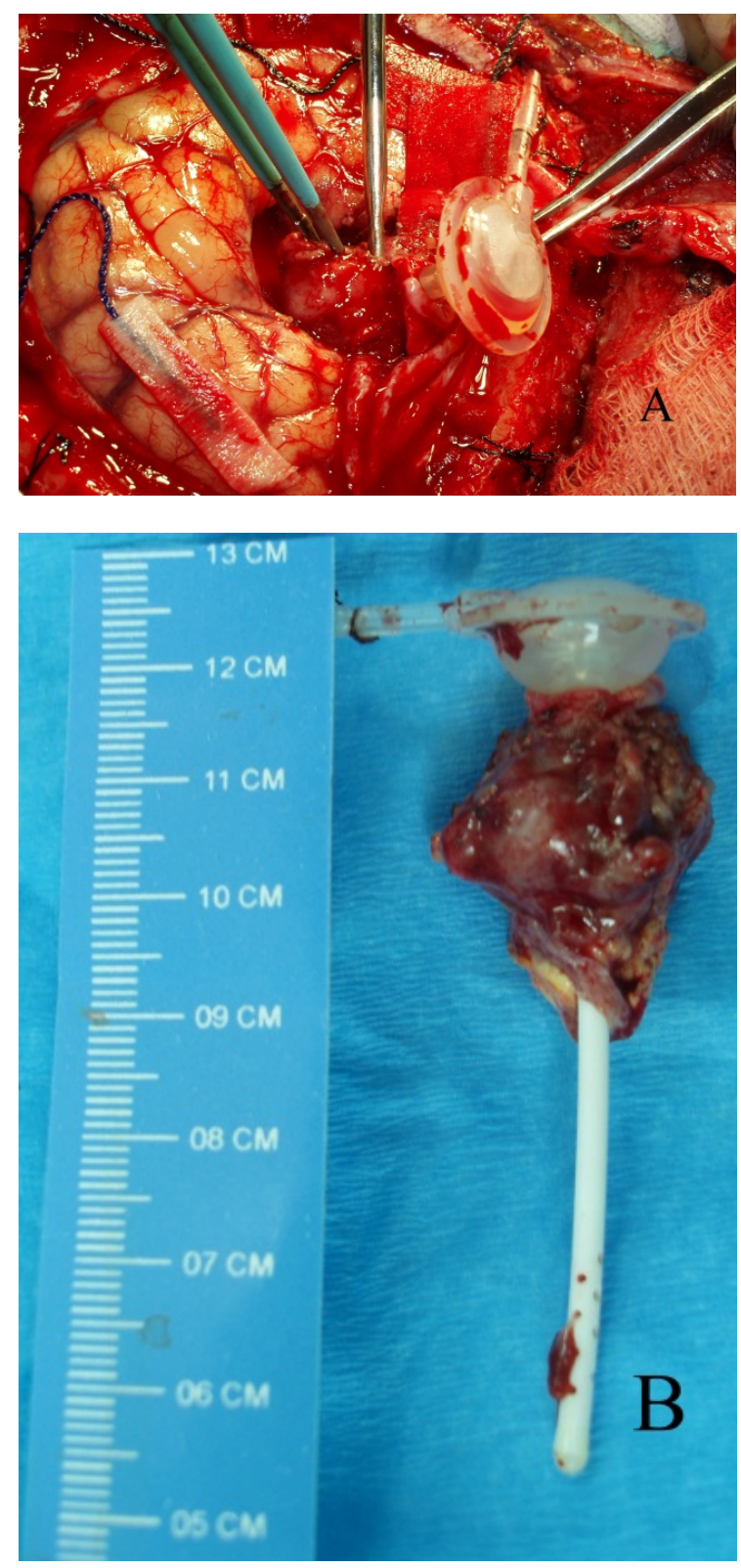

Figure 2

(A)Right fronto-parietal craniotomy, note the tumor cuddling the shunt hardware. (B) A lesion of grayishwhite appearance, rubbery consistency, and regularly vascularized, enveloped the catheter valve so both were removed entirely

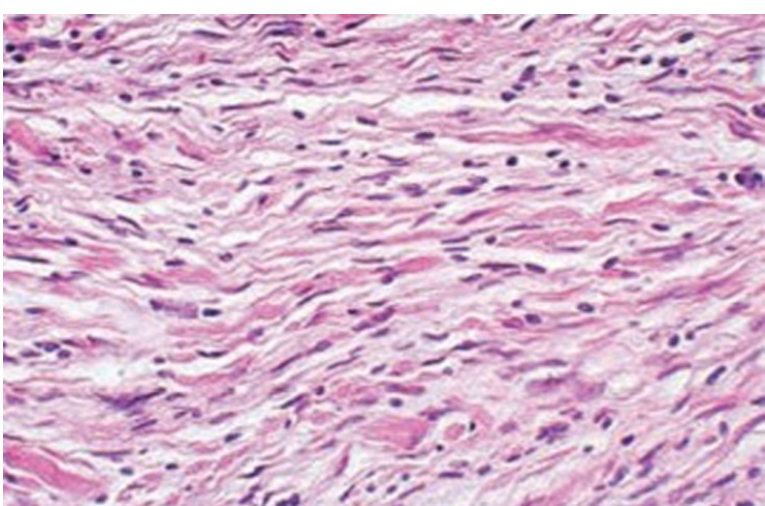

Figure 3

The definitive histopathological study reported a meningothelial cell neoplasm arranged in spindleshaped beams, in parallel and intertwined with a collagen-rich matrix, conclusive of meningioma

Meningiomas have been described in the context of foreign bodies(14), radiation exposure $(14,15,3)$, brain abscess $(13,16)$, head injury (1), exogenous or endogenous hormones $(11,4)$, among others. However, only ionizing radiation has been identified as an etiologic agent likely to be correlated with the occurrence of these tumors. The role of head trauma, viral infection, and sex hormones is less certain (9).

In 1999, Holthouse et al (7)reported the case of a 25-year-old man with a history of childhood cerebellar glioma treated by surgical removal, radiotherapy and a VP shunt presented with a 5 month history of frontal headaches. Imaging revealed a mass surrounding the shunt, which was surgically removed but in this case the shunt was left in situ, unlike our case. The histopathological examination revealed an atypical and invasive meningioma; thus, to our knowledge the case we present is the first case of meningioma related to VP shunt hardware without prior radiation exposure.

There are factors strongly associated with risk of developing meningioma, as in the case of exposure to ionizing radiation, 
or exogenous or endogenous hormones, as in this case, the presence of shunt material as a foreign body may have contributed to oncogenesis on the basis of a chronic inflammatory reaction.

\section{Competing interests}

None declared.

\section{Funding}

None.

\section{Ethical approval}

Not required.

\section{Abbreviations \\ WHO: World Health Organization \\ GCS: Glasgow Coma Scale \\ MRI: Magnetic Resonance Imaging \\ VP: Ventriculoperotoneal}

\section{Correspondence:}

Dr. Luis Rafael Moscote, Universidad de

Cartagena, Cartagena de Indias, Colombia.

E-mail:Mineurocirujano@aol.com

\section{References}

1. Annegers JF, Laws ER, Kurland LT, Grabow JD. Head trauma and subsequent brain tumors. Neurosurgery 1979; 4:203-6. Available:

http://www.ncbi.nlm.nih.gov/pubmed/460549. Accessed 4 May 2013

2. Buetow MP, Buetow PC, Smirniotopoulos JG. Typical, atypical, and misleading features in meningioma. Radiographics 1991; 11:1087-106. Available:

http://www.ncbi.nlm.nih.gov/pubmed/1749851. Accessed 4 May 2013

3. Daentzer D, Böker DK. (Radiation-induced meningioma 20 years after operation and high-dose irradiation of an ependymoma). Zentralbl Neurochir 1999; 60:27-32. Available:

http://www.ncbi.nlm.nih.gov/pubmed/10356722.

Accessed 4 May 2013

4. Frassanito P, De Bonis P, Mattogno PP, Novello M, Anile C. Hormonal therapy for fertility and huge meningioma: a purely random association? Acta Neurol Belg 2012; 112:299-301. Available:

http://www.ncbi.nlm.nih.gov/pubmed/22426675.

Accessed 4 May 2013
5. Gelabert-González M, Serramito-García R. (Intracranial meningiomas: I. Epidemiology, aetiology, pathogenesis and prognostic factors). Rev Neurol 2011; 53:165-72. Available:

http://www.ncbi.nlm.nih.gov/pubmed/21748714.

Accessed 4 May 2013

6. Hallinan JTPD, Hegde AN, Lim WEH. Dilemmas and diagnostic difficulties in meningioma. Clin Radiol 2013; Available:

http://www.ncbi.nlm.nih.gov/pubmed/23623578.

Accessed 4 May 2013

7. Holthouse DJ, Robbins PD, Lee MA. Ventriculoperitoneal shunt related meningioma following excision and radiotherapy for glioma. J Clin Neurosci 1999; 6:347-348. Available:

http://www.sciencedirect.com/science/article/pii/S09675 86899900632.

8. Iaconetta G, Santella A, Friscia M, Abbate V, Califano L. Extracranial primary and secondary meningiomas. International Journal of Oral and Maxillofacial Surgery 2012; 41:211-217. Available:

http://www.sciencedirect.com/science/article/pii/S09015 02711014056.

9. Longstreth WT, Dennis LK, McGuire VM, Drangsholt MT, Koepsell TD. Epidemiology of intracranial meningioma. Cancer 1993; 72:639-48. Available:

http://www.ncbi.nlm.nih.gov/pubmed/8334619.

Accessed 10 April 2013

10. Louis D, Scheithauer B, Budka H, Von Deimling A, Kepes J. Meningiomas, in Kleihues P, Cavenee W (eds): Pathology and genetics. Tumours of the nervous system, WHO classification of tumors. IARC Press: Lyon, 2000, pp.176-84

11. Markopoulos C, Sampalis F, Givalos N, Gogas H. Association of breast cancer with meningioma. Eur J Surg Oncol 1998; 24:332-4. Available:

http://www.ncbi.nlm.nih.gov/pubmed/9725004.

Accessed 4 May 2013

12. Marosi C, Hassler M, Roessler K, Reni M, Sant M, Mazza E, et al. Meningioma. Critical Reviews in Oncology/Hematology 2008; 67:153-171. Available: http://www.sciencedirect.com/science/article/pii/S10408 4280800022X.

13. Reichenthal E, Rubinstein AB, Shevach I, Cohen ML. Meningioma presenting at a site of a previously aspirated brain abscess. Acta Neurochir (Wien) 1991; 109:142-4. Available:

http://www.ncbi.nlm.nih.gov/pubmed/1858532.

Accessed 4 May 2013

14. Saleh J, Silberstein HJ, Salner AL, Uphoff DF. Meningioma: the role of a foreign body and irradiation in tumor formation. Neurosurgery 1991; 29:113-8; discussion 118-9. Available: http://www.ncbi.nlm.nih.gov/pubmed/1870671. 
DOI: 10.2478/romneu-2013-0012

Accessed 4 May 2013

15. Strojan P, Popović M, Jereb B. Secondary intracranial meningiomas after high-dose cranial irradiation: report of five cases and review of the literature. Int J Radiat Oncol Biol Phys 2000; 48:65-73. Available:

http://www.ncbi.nlm.nih.gov/pubmed/10924973.

Accessed 4 May 2013

16. Sussman S, TerBrugge KG, Solt LC, Deck JH. Thorotrast-induced meningioma. Case report. J Neurosurg 1980; 52:834-7. Available:

http://www.ncbi.nlm.nih.gov/pubmed/7381542.

Accessed 4 May 2013

17. Viswanathan A, Demonte F. Tumors of the meninges. Handbook of clinical neurology 2012; 105:641-56. Available:

http://www.ncbi.nlm.nih.gov/pubmed/22230524.

Accessed 4 May 2013

18. Weller RO. Microscopic morphology and histology of the human meninges. Morphologie 2005; 89:22-34. Available:

http://www.ncbi.nlm.nih.gov/pubmed/15943078.

Accessed 21 April 2013

19. Wiemels J, Wrensch M, Claus EB. Epidemiology and etiology of meningioma. J Neurooncol 2010; 99:307-14. Available:

http://www.pubmedcentral.nih.gov/articlerender.fcgi?ar tid $=2945461 \&$ tool $=$ pmcentrez\&rendertype $=$ abstract.

Accessed 11 March 2013

20. Wieseler-Frank J, Jekich BM, Mahoney JH, Bland ST, Maier SF, Watkins LR. A novel immune-to-CNS communication pathway: cells of the meninges surrounding the spinal cord CSF space produce proinflammatory cytokines in response to an inflammatory stimulus. Brain Behav Immun 2007; 21:711-8. Available:

http://www.ncbi.nlm.nih.gov/pubmed/16989980.

Accessed 18 March 2013 